\title{
Challenges and barriers to start isotretinoin in acne patients
}

\section{Mana A Alharbi}

Department of Dermatology, Imam Muhammad ibn Saud Islamic University (IMSIU), Riyadh, Saudi Arabia

\section{RESEARCH}

Please cite this paper as: Alharbi MA. Challenges and barriers to start isotretinoin in acne patients. AMJ 2020;13(4):142-147.

https://doi.org/10.35841/1836-1935.13.4.142-147

\section{Corresponding Author:}

Mana Alharbi

Dermatology department, College of medicine, Imam Muhammad ibn Saud Islamic University (IMSIU), Riyadh, Saudi Arabia

Email: dr.badrani@hotmail.com

\section{ABSTRACT}

\section{Background}

The awareness of patients with acne about the side effects of isotretinoin is an important factor to reduce noncompliance with isotretinoin therapy, especially with longterm use.

\section{Aims}

The objective was to assess gender-specific awareness and concerns of isotretinoin among patients with acne.

\section{Methods}

A cross-sectional survey study was conducted among acne patients of both genders attending dermatology outpatient clinics at a tertiary care hospital.

\section{Results}

A total 356 acne patients were included in the current analysis. The average age was $23.6 \pm 5.8$ years. More than half of the patients ( 57.6 per cent) were females and the majority (79.5 per cent) were single. The majority of the patients were aware of isotretinoin (79.1 per cent) and its side effects ( 63.0 per cent). The most frequently recognized side effect was dryness (55.1 per cent), followed by teratogenicity (28.5 per cent), disturbance of lipid profile
(9.3 per cent), and finally constipation (7.0 per cent). Compared to males, females were more likely to know and to be concerned about the teratogenic side effect of isotretinoin ( $p=0.022$ and $p<0.001$, respectively). The most important source of information about isotretinoin was physician (61.9 per cent), followed by patients (13.9 per cent), friends (8.8 per cent), and finally internet (8.1 per cent).

\section{Conclusion}

The awareness of specific isotretinoin side effects among a group of young Saudi patients with acne was suboptimal. Females were more likely to be aware of and concerned about the teratogenic side effect isotretinoin. The majority of our patients prefer to receive isotretinoin information from trusted official sources. The findings highlight the dermatologist role in health education and counselling on acne and its treatments.

\section{Key Words}

Acne vulgaris, isotretinoin, therapy, side effects, awareness, Saudi Arabia

\section{What this study adds:}

\section{What is known about this subject?}

As expected, female patients were more aware of and concerned about the teratogenic side effect isotretinoin

\section{What new information is offered in this study?}

The majority of our patients prefer to receive isotretinoin information from trusted official sources. The findings highlight the dermatologist role in health education and counselling on acne and its treatments.

3. What are the implications for research, policy, or practice?

The awareness of specific isotretinoin side effects among a group of young Saudi patients with acne was suboptimal so education is a very essential for acne patients.

\section{Background}

Acne vulgaris is a very common chronic inflammatory 
dermatosis affecting up to 85 per cent of adolescents and young adults, with more than 20 per cent of the patients have moderate to severe disease. ${ }^{1}$ In Saudi Arabia, studies showed that more than half of the University students have acne. ${ }^{2,3}$ As acne can be complicated by skin scaring and pigmentation, it can have a negative impact of the body image, especially at the time the adolescent is undergoing major physical, intellectual and emotional transformations. $^{4,5}$ This may leads to psychological problems such as depression, anxiety, and low selfesteem. ${ }^{4,5}$ Additionally, it can negatively impact the quality of life. ${ }^{6}$ The challenges facing acne patients place pressure on dermatologists to provide an effective and safe treatment, especially for patients with severe acne. ${ }^{7}$

There are several medications used for the treatment of acne. ${ }^{8,9}$ Oral isotretinoin which is a vitamin A derivatives is considered one of the most effective treatments for acne vulgaris. ${ }^{10}$ Oral isotretinoin is usually used to treat severe and refractory cases that are not responsive to traditional treatments, such as antimicrobials, hormones, and topical treatments. $^{8} \quad$ Additionally, low-dose isotretinoin is frequently used to treat mild to moderate grades of acne. ${ }^{11}$ However, several side effects of isotretinoin have been reported including; skin dryness, elevated liver enzymes, disturbed blood lipids, depression, and teratogenicity. ${ }^{10,12}$ Although not very common, these side effects may force the patient to stop isotretinoin therapy. ${ }^{12}$ Therefore, the awareness of the patients with these side effects is an important factor to reduce non-compliance with isotretinoin therapy, especially with long-term use. ${ }^{13}$

The objective of the current study was to assess the awareness, concerns, and use of isotretinoin among patients with acne attending dermatology clinic. Additionally, to explore whether gender is playing any role in such awareness.

\section{Method}

\section{Setting}

The current study was done at the dermatology outpatient clinics at tertiary care hospital. It is governmentally funded and provides free medical care. On average, the dermatology outpatient clinics serve approximately 300 patients per day

\section{Design and population}

It was a cross-sectional survey study done among acne patients of both genders attending the dermatology outpatient clinics during June 2017. Ethical approval was obtained from the local research ethics committee. There were no exclusions based on the type, the severity, or the duration of the disease.

\section{Data collection and recruitment}

The study questionnaire was created by the study investigators. It included questions about the demographics of the patients as well as the awareness and use of isotretinoin. All consecutive acne patients attending the dermatology outpatient clinics during the study period were invited to join the study and to explain the study objectives. Filling the questionnaire was considered as approval to join the study. Out of 593 patients approached, 356 completed the study questionnaire (response rate of 60 per cent)

\section{Statistical analysis}

Categorical variables were presented as frequencies and percentages. Continuous variables were presented as means and standard deviations (SD). Chi-squared test or Fisher's exact test, as appropriate, were used to compare the awareness and use between males and females. All Pvalues were two-tailed. A p-value $<0.05$ was considered as significant. Statistical Package for the Social Sciences software (SPSS Version 25.0. Armonk, NY: IBM Corp) was used for all statistical analyses.

\section{Results}

A total 356 acne patients were included in the current analysis. As shown in Table 1, the average age was 23.6 \pm 5.8 years. More than half of the patients (57.6 per cent) were females and the majority (79.5 per cent) were single. More than half of the patients ( 51.4 per cent) had a university education, with few (17.4 per cent) had less than high school education.

Table 2 shows the awareness and use of isotretinoin among the study participants by gender. The majority of the patients were aware of isotretinoin (79.1 per cent) and its side effects (63.0 per cent). The most frequently recognized side effect was dryness (55.1 per cent), followed by teratogenicity (28.5 per cent), disturbance of lipid profile (9.3 per cent), and finally constipation (7.0 per cent). The majority (86.6 per cent) of the patients were ready to use isotretinoin. However, the side effects of the drug were a considerable concern for the patients (54.8 per cent), followed by the duration of therapy (35.6 per cent) and teratogenicity ( 9.6 per cent). Approximately 21.2 per cent of the patients were using isotretinoin at the time of the study. The majority of the patients had/thought side effects can interfere with your daily activities. Dryness of the lips and face were the most reported side effects. Compared to males, females were more likely to know and to be 
concerned about the teratogenic side effect of isotretinoin $(p=0.022$ and $p<0.001$, respectively). Additionally, females were more ready to use isotretinoin $(p=0.002)$ and less concerned about the impact of the side effects on their daily activities $(p=0.012)$.

As shown in Figure 1, the most important source of information about isotretinoin in both genders was physician (49.6 per cent in males, 70.9 per cent in females, and 61.9 per cent in all patients), followed by patients (13.9 per cent), friends (8.8 per cent), and internet (8.1 per cent). Compared to males, females were more likely to get information from physicians rather than previous patients $(p<0.001)$.

\section{Discussion}

The current study presents data about the awareness, concerns, and use of isotretinoin among a group of young Saudi attending dermatology clinic. Irrespective of gender, the awareness of specific isotretinoin side effects in our patients was suboptimal. This was consistent with previous studies done in Saudi Arabia that showed low awareness of acne and treatment. ${ }^{3,14}$ As expected, female patients were more aware of and concerned about the teratogenic side effect isotretinoin. As one-fifth of our patients were married, dermatologists are strongly encouraged to council female patients with acne about the teratogenic effects of isotretinoin and to provide advice on appropriate contraceptive methods. ${ }^{15}$ This may improve the safety of and compliance with isotretinoin use. ${ }^{15}$ However, in many situations dermatologists are not abiding with protecting against teratogenicity in their female patients. ${ }^{16,17}$

Despite being a major safety concern, teratogenicity was not the main concern of our patients before starting the drug. Instead, dryness and duration of therapy were the main concerns. This may reflect the fact that approximately 80 per cent of our patients were single. On the other hand, the high concern about dryness may reflect the additional worry about facial appearance, which may affect daily activities and long-term use of the drug. Furthermore, the high concern about duration of therapy may be driven by higher risk of developing side effects.

Doctors were the primary source of information about isotretinoin in our acne patients. Unexpectedly, social media and internet which is extensively used by young Saudi were the least sources of information. ${ }^{18}$ Both finding may indicate that our patients, who were more educated than typical Saudi patients, prefer to receive isotretinoin information from trusted official sources. ${ }^{18}$ This put more emphasis of the dermatologist role in health education and counselling on acne and its treatments.

\section{Conclusion}

In conclusion, the awareness of specific isotretinoin side effects among a group of young Saudi patients with acne was suboptimal. Compared to males, females were more likely to be aware of and concerned about the teratogenic side effect isotretinoin. The majority of our patients prefer to receive isotretinoin information from trusted official sources. The findings highlight the dermatologist role in health education and counselling on acne and its treatments.

\section{References}

1. Bhate $\mathrm{K}$, Williams HC. Epidemiology of acne vulgaris. $\mathrm{Br} \mathrm{J}$ Dermatol. 2013;168(3):474-485.

2. Abo El-Fetoh NM, Alenezi NG, Alshamari NG, et al. Epidemiology of acne vulgaris in adolescent male students in Arar, Kingdom of Saudi Arabia. J Egypt Public Health Assoc. 2016;91(3):144-149.

3. Al Robaee AA. Prevalence, knowledge, beliefs and psychosocial impact of acne in University students in Central Saudi Arabia. Saudi Med J. 2005;26(12):19581961.

4. Feton-Danou N. Psychological impact of acne vulgaris. Ann Dermatol Venereol. 2010;137 Suppl 2:S62-65.

5. Revol O, Milliez N, Gerard D. Psychological impact of acne on 21st-century adolescents: decoding for better care. Br J Dermatol. 2015;172 Suppl 1:52-58.

6. Alanazi MS, Hammad SM, Mohamed AE. Prevalence and psychological impact of Acne vulgaris among female secondary school students in Arar city, Saudi Arabia, in 2018. Electron Physician. 2018;10(8):7224-7229.

7. Strauss JS, Krowchuk DP, Leyden JJ, et al. Guidelines of care for acne vulgaris management. J Am Acad Dermatol. 2007;56(4):651-663.

8. Zaenglein AL, Pathy AL, Schlosser BJ, et al. Guidelines of care for the management of acne vulgaris. J Am Acad Dermatol. 2016;74(5):945-973 e933.

9. Savage $\amalg$, Layton AM. Treating acne vulgaris: systemic, local and combination therapy. Expert Rev Clin Pharmacol. 2010;3(4):563-580.

10. Charakida A, Mouser PE, Chu AC. Safety and side effects of the acne drug, oral isotretinoin. Expert Opin Drug Saf. 2004;3(2):119-129.

11. Sardana K, Garg VK. Efficacy of low-dose isotretinoin in acne vulgaris. Indian J Dermatol Venereol Leprol. 2010;76(1):7-13.

12. Vallerand IA, Lewinson RT, Farris MS, et al. Efficacy and adverse events of oral isotretinoin for acne: a systematic 
review. Br J Dermatol. 2018;178(1):76-85.

13. Biset $N$, Lelubre $M$, Senterre $C$, et al. Assessment of medication adherence and responsible use of isotretinoin and contraception through Belgian community pharmacies by using pharmacy refill data. Patient Prefer Adherence. 2018;12:153-161.

14. Younis NS, Al-Harbi NY. Public Understanding and Awareness of Isotretinoin Use and Safety in Al Ahsa, Eastern Saudi Arabia. Ther Innov Regul Sci. 2018:2168479018807677.

15. Werner CA, Papic MJ, Ferris LK, et al. Promoting safe use of isotretinoin by increasing contraceptive knowledge. JAMA Dermatol. 2015;151(4):389-393.

16. AlGhamdi KM, Khurram H, Asiri YA, et al. Dermatologists' level of compliance with the prescription guidelines of isotretinoin for females of childbearing potential. Int J Dermatol. 2011;50(9):1094-1098.

17. Crijns HJ, Straus SM, Gispen-de Wied C, et al. Compliance with pregnancy prevention programmes of isotretinoin in Europe: a systematic review. $\mathrm{Br} J$ Dermatol. 2011;164(2):238-244.

18. Alhaddad MS. The use of social media among Saudi residents for medicines related information. Saudi Pharm J. 2018;26(8):1106-1111.

\section{PEER REVIEW}

Not commissioned. Externally peer reviewed.

\section{CONFLICTS OF INTEREST}

The authors declare that they have no competing interests.

\section{FUNDING}

None

\section{ETHICS COMMITTEE APPROVAL}

Ethical approval was obtained from the local research ethics committee 
Table 1: demographics of the study participants

\begin{tabular}{|l|c|}
\hline \multicolumn{1}{|c|}{ Characteristics } & Value* \\
\hline Age in years (mean \pm SD) & $23.6 \pm 5.8$ \\
\hline Gender & $151(42.4 \%)$ \\
\hline Male & $205(57.6 \%)$ \\
\hline Female & $283(79.5 \%)$ \\
\hline Marital status & $73(20.5 \%)$ \\
\hline Single & $17(4.8 \%)$ \\
\hline Married & $45(12.6 \%)$ \\
\hline Educational level & $111(31.2 \%)$ \\
\hline Primary school or less & $183(51.4 \%)$ \\
\hline Intermediate school & \\
\hline High school & \\
\hline University & \\
\hline
\end{tabular}

* Number (percentage) unless mentioned otherwise

Table 2: Awareness and use of isotretinoin among the study participants by gender*

\begin{tabular}{|c|c|c|c|c|}
\hline Characteristics & Males & Females & Total & P-value \\
\hline \multicolumn{5}{|l|}{ Did you hear of isotretinoin? } \\
\hline Yes & $114(78.1 \%)$ & $159(79.9 \%)$ & $273(79.1 \%)$ & 0.682 \\
\hline No & $32(21.9 \%)$ & $40(20.1 \%)$ & $72(20.9 \%)$ & \\
\hline \multicolumn{5}{|c|}{ Do you know the drug side effects? } \\
\hline Yes & $99(68.8 \%)$ & $116(58.9 \%)$ & $215(63.0 \%)$ & 0.062 \\
\hline No & $45(31.3 \%)$ & $81(41.1 \%)$ & $126(37.0 \%)$ & \\
\hline \multicolumn{5}{|c|}{ What side effects do you know? } \\
\hline Dryness & $57(59.4 \%)$ & $61(51.7 \%)$ & $118(55.1 \%)$ & 0.022 \\
\hline Teratogenicity & $18(18.8 \%)$ & $43(36.4 \%)$ & $61(28.5 \%)$ & \\
\hline Disturbance of lipid profile & $12(12.5 \%)$ & $8(6.8 \%)$ & $20(9.3 \%)$ & \\
\hline Constipation & $9(9.4 \%)$ & $6(5.1 \%)$ & $15(7.0 \%)$ & \\
\hline \multicolumn{5}{|c|}{ Do you think you are ready to use it? } \\
\hline Yes & $111(79.9 \%)$ & $181(91.4 \%)$ & $292(86.6 \%)$ & 0.002 \\
\hline No & $28(20.1 \%)$ & $17(8.6 \%)$ & 45 (13.4\%) & \\
\hline \multicolumn{5}{|c|}{$\begin{array}{l}\text { What are your concerns before starting } \\
\text { the drug? }\end{array}$} \\
\hline Side effects in general & $60(51.7 \%)$ & $100(56.8 \%)$ & $160(54.8 \%)$ & $<0.001$ \\
\hline Teratogenicity & $0(0.0 \%)$ & $28(15.9 \%)$ & $28(9.6 \%)$ & \\
\hline Duration of therapy & $56(48.3 \%)$ & $48(27.3 \%)$ & $104(35.6 \%)$ & \\
\hline Are you currently using isotre & & & & \\
\hline
\end{tabular}




\begin{tabular}{|c|l|l|l|c|}
\hline Yes & $29(21.6 \%)$ & $42(20.9 \%)$ & $71(21.2 \%)$ & 0.870 \\
\hline No & $105(78.4 \%)$ & $159(79.1 \%)$ & $264(78.8 \%)$ & \\
\hline $\begin{array}{l}\text { Did you have/think side effects can } \\
\text { interfere with your daily activities? }\end{array}$ & & & & \\
\hline Yes & $81(72.3 \%)$ & $86(57.3 \%)$ & $167(63.7 \%)$ & 0.012 \\
\hline No & $31(27.7 \%)$ & $64(42.7 \%)$ & $95(36.3 \%)$ & \\
\hline
\end{tabular}

* Number (percentage), $\mathrm{p}$-value were derived from chi square

Figure 1: Sources of information about isotretinoin among the study participants by gender $P<0.001$

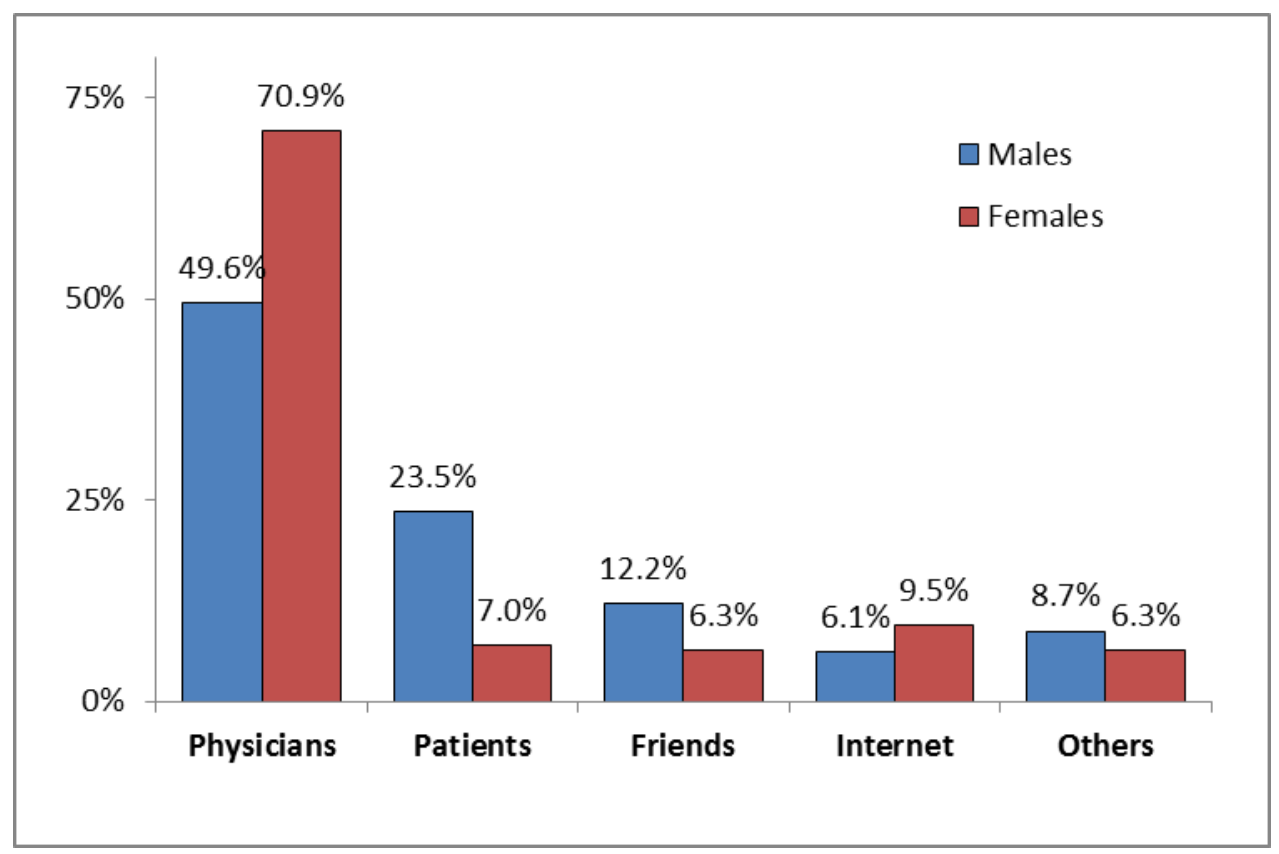

